\title{
FACTORS INFLUENCING THE ADOPTION OF SOCIAL MEDIA IN SMALL AND MEDIUM ENTERPRISES (SMES)
}

\author{
Amiruddin Ahamat ${ }^{1}$, Muhamad Sham Shahkat Ali $^{2 \star}$ and Norfaziela Hamid ${ }^{3 *}$ \\ 1Dr., Universiti Teknikal Malaysia Melaka, Malaysia, amiruddin@utem.edu.my \\ ${ }^{2}$ Assoc. Prof. Dr., Abu Dhabi University, United Arab Emirates, muhamad.sham@adu.ac.ae \\ ${ }^{3}$ Ms., Universiti Teknikal Malaysia Melaka, Malaysia \\ ${ }^{*}$ Corresponding author
}

\begin{abstract}
Small and Medium Enterprises (SMEs) industry has developed rapidly and it has become one of the major contributors to the Malaysian economy. This research is focused on the food and beverage industry at Halal SMEs which were developed to become export-ready so that they will gradually become a global player. Social media can be described as a newly emerging phenomenon in which it has evolved the business operating environment in Malaysia. Additionally, social media allows businesses to communicate speedily and cheaply with customers. It is also a medium to build a strong customer and public relationship, market development and to gain information that can be used to generate business leads that may increase sales and thus grows the Halal SMEs. This research will also focus on the factors influencing the adoption of social media in Halal SMEs. The social media adoption models were developed from the theory of Technology Acceptance Model (TAM) by including the perceived usefulness, perceived ease of use and perceived trust. The survey method was chosen in order to prove the factors influencing the adoption of social media among Halal SMEs. The result showed that all the three variables (perceived usefulness, perceived ease of use and perceived trust) in this study have their relationship with the dependent variables (adoption of social media). From the regression analysis result, perceived usefulness is the highest factor that influences the adoption of social media in food and beverage industry at Halal SMEs.
\end{abstract}

Keywords: Small and Medium Enterprises (SMEs), halal, food and beverage industry, social media, Technology Acceptance Model (TAM)

\section{INTRODUCTION}

Social media was transitioned from fad to mainstream to global phenomena over the last few years. Nowadays, social media's reputation keeps growing, connecting everyone with almost everything that they watch, and the concept of social media on business becomes very popular in Malaysia. Social media is developing the opportunities to the growth of SMEs industry and offers many benefits as well as problems that SME's need to be aware of and to deal with it in an efficient way. This research focuses only on food 
and beverage industry at Halal Small and Medium Enterprises (SMEs).

Recently, SME's have grown in this global economy. However, the potential of social media is still under exploited by some SMEs. According to Baird and Parasnis (2011), with the global outpouring of social media usage, many businesses are experiencing tremendous pressure to extend to where their customers are paying attention. In the present day, the heart of customer activity is progressively becoming virtual, situated inside a social media or social networking site. Entrepreneurs enact opportunities by acquiring technology, and extracting cues that supply them with information that is relevant, sensible, convincing and logical (Ahamat \& Chong, 2014).

Furthermore, social media has been an important element of marketing strategy among small enterprises simply because of its cost-effectiveness, the ability to achieve targeted consumers rapidly and also gain more leads or sales. With a minimum investment, companies can adopt the social media effectively, also offering useful information and understanding over the products and services of the enterprise. According to Soh et al. (1997), if SMEs implement the internet in their company, potential commercial functions can be performed, which include: marketing themselves both locally and globally; gathering business information and consumer's feedback; providing customer support; and conducting electronic transactions. The social media offers advantage towards SMEs this is because it created mechanisms for achieving sustainable competitive benefits. Social media can claim to be one of these mechanisms plus there is need to carry out a research in order to have a proper understand about the good influence factors of social media adoption in Halal SMEs.

\subsection{Problem Statement}

In a challenging world today, SMEs has to move towards the technology and keep advance in commercialization of their business and makes the business most success from the other companies. Through the appearance of new players and industries, organizations especially the SMEs might no longer really rely through the traditional way of performing business in order to survive as well as grow. Social media has recently developed to be an essential platform for the vendors to achieve their audiences. Apart from that, understanding the factors that influence the adoption of social media can encourage organization in choosing the social media to be use and exactly know the best way to organize their own social media content.

Furthermore, the proper understanding of social media tools has not yet fully achieved. According to Business Wire (2012), a number of SMEs report shows that social media has a rapid effect on the growth of sales and employment rate in their enterprises. It needs to prove that there is a good and beneficial factors to adopt the social media in SMEs organization on developing the success business. Thus, social media is important to develop or enhance and to achieve the success business. This is the reason why the researchers study on the factors influencing the adoption of social media in the Halal SMEs and find out the factor that most contribute to the adoption of the social media. Next, with the good reason and good factors, it will show why Halal SMEs need to adopt social media within their organization.

\subsection{Research Question and Research Objective}

These are the research question that qualified for this research study:

RQ1) What are the relationship between the factors influence and the adoption of social media in Halal SMEs?

RQ2) What are the factors that influence more to the adoption of the social media in Halal SMEs?

The objectives of the research are as follows:

RO1) To determine the relationship between the factors influence and the adoption of social media in Halal SMEs;

RO2) To investigate the factors that influence more to the adoption of social media in Halal SMEs.

\section{LITERATURE REVIEW}

Small and medium enterprises (SMEs) play a vital role in the Malaysian economy and are considered to be the backbone of industrial development in the country (Saleh and Ndubisi, 2006, Ramayah et. al., 2002). Now, SMEs industry is one of the key drivers in The Government and Economy Transformation Programs for Malaysia and it is including the Halal SMEs. Most new phenomena appear and vanish on a regular basis. Social media is one such phenomenon. Social media was called as a word-of-mouth marketing which has 
received a technology makeover. Many marketers still focus on the tactics around social media even over the past couple of years in social media's emergence. The primary purpose of this research is to determine the relationship between the factors influence and the adoption of social media and to investigate the factor that most contribute to the adoption of social media. Theory of Technology Acceptance Model (TAM) (Davis, 1989) will be used to explain this research study in more details.

\subsection{Small and Medium Enterprises (SMEs)}

A number of studies have used the number of employees as a measure of enterprise size (Thong 1999; Kartiwi \& MacGregor, 2007). Other studies have identified enterprise size based on annual turnover (Ramamurthy, et al., 1999). Some studies have applied both the number of employees and the revenue as indicators of enterprise size. SMEs are, arguably, the bedrock of any developing economy. In general, SME is the base upon which future economic and employment growth can be built. SMEs over the world remain buoyant despite mounting economic and social hardships (Saleh \& Ndubisi, 2006). Furthermore, economists agree that SMEs play a vital role in the socio-economic fabric of the world. With all changes and the growing demand for higher quality modern products and services, many traditional SMEs over the world face closure or difficulties upgrading. Even modern SMEs in developed countries face very difficult competitive challenges in the emerging setting (Sanjay, 2000). Small and Medium Enterprises (SMEs) are perceived as the engine of growth in Malaysia because of their key role in economic development. The development of the halal industry in Malaysia was parallel with the development of the small and medium enterprises (SMEs) that may penetrate the global halal market. The National SME Development Council highlights that the Halal industry is one out of the primary areas whereby SMEs come with a high growth potential. The government also believes that with all these various incentives and efforts, Malaysian SMEs in the Halal food sector will be on track to increase their presence in the international market.

\subsubsection{Social Media}

Family firms make sense of personal and formal networks to connect their business and to gain access to key information and decision makers (Ahamat \& Chong, 2015). Facebook, Skype and discussion forums are examples of social media networks (Tapscott and Williams, 2008) that facilitate access to such critical and valuable information. Kaplan and Haenlin (2010) bring forth that media richness theory is based on the supposition that the goal of any communication is the resolution of ambiguity and the reduction of uncertainty. The theory claims that media differ in the level of richness they possess - the amount of information they allow to be transmitted in a given interval. Therefore, certain media become more effective as opposed to others. Self-presentation theory states that in any type of social interaction, people have the desire to control the impressions other people form of them. This is done with the aim of influencing others so you will get rewarded, as well as a wish to create an image that is consistent with one's individual personality (Kaplan and Haenlein, 2010).

In Malaysia, the most popular and trending types of social media are mostly same as shown by Kaplan and Haenlein but it was more on Facebook, Twitter, Google+, Youtube, Yahoo, Linkedin, Blogs and Wikis. The use of social media ranges from personal to business purposes. It can also aid the development of a firm's worthiness, increase the customer and supplier contacts, brings to light where resources and funding are available, promote innovation and help in the cultivation of strategic partnerships (Zontanos and Anderson, 2004). Both businesses and consumers are using the media to share information, exchange opinions and recommendations and display certain consumption behavior (Kotler and Armstrong, 2011).

According to the 2012 social media marketing report, Stelzner (2012) stated that $83 \%$ of marketers consider social media as important for businesses. Marketers can no longer rely on mass media channels alone to communicate with their consumers. They must adopt new strategies if they wish to succeed (Kotler and Armstrong, 2011). The impacts of globalization have pressured SMEs to greater demands. The use of social technologies provides insights, thoughts and ideas on how to better serve customers and enables businesses to discover innovative ways to conduct business or new products and services to offer customers (Evans and McKee, 2010).

\subsubsection{Social Media Adoption Factors by Using Technology Acceptance Model (TAM) Theory}

The Technology Acceptance Model (TAM) was originally introduced and studied as a means of understanding how users adopt and use new technology by evaluating the factors that influenced the decision to accept a new technology (Davis 1989). In this research study, the constructs Perceived Usefulness (PU) and Perceived Ease of Use (PEoU) towards the adoption of social media were adapted 
from TAM. Perceived usefulness and perceived ease of use of a technology integrated to generate influencing decisions of whether to adopt the technology. Accordingly, perceived usefulness and ease of use might not exactly completely give an explanation for the adoption of social media. Prior studies have extended the original TAM by adding constructs, such as perceived playfulness (Moon and Kim, 2001), perceived enjoyment (Koufaris, 2002) and perceived credibility, (Wang et al, 2003). Considering the context of social media, this research extends TAM by including perceived trust (PT) into the model to describe acceptance of social media.

\subsubsection{Theoretical Framework}

The theoretical framework is constructed to describe the relationship between the different variables plays in this research.

Figure 1. Theoretical Framework

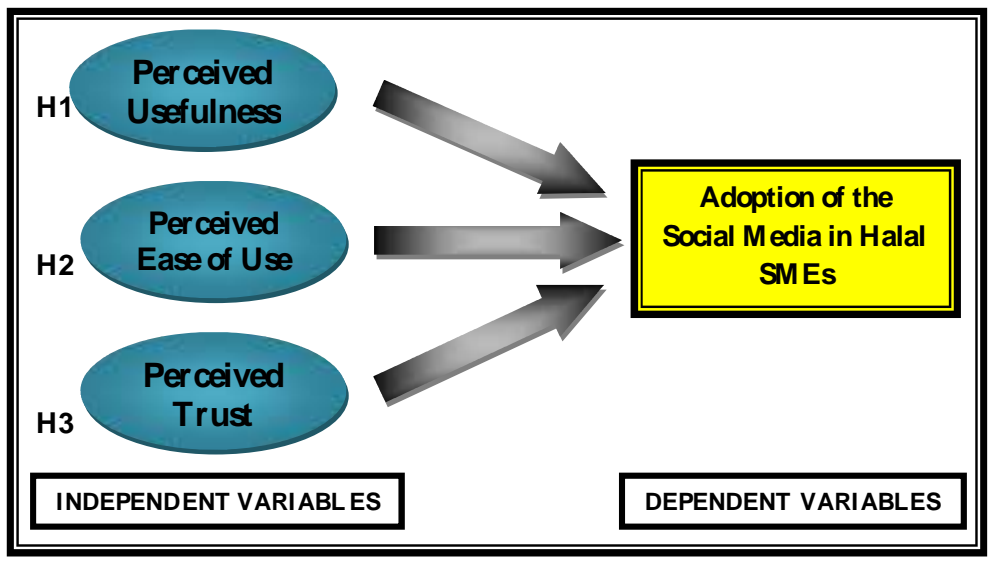

\subsubsection{Hypothesis}

\begin{tabular}{|c|l|}
\hline H10 & $\begin{array}{l}\text { Perceived usefulness has no rel ationship with the adoption of social media in } \\
\text { Halal SMEs }\end{array}$ \\
\hline $\mathbf{H 1}_{1}$ & $\begin{array}{l}\text { Perceived usefulness has relationship with the adoption of social media in } \\
\text { Halal SMEs }\end{array}$ \\
\hline
\end{tabular}

\begin{tabular}{|l|l|}
\hline $\mathbf{H 2}$ & $\begin{array}{l}\text { Perceived ease of use has no relationship with the adoption of social media } \\
\text { in Halal SMEs }\end{array}$ \\
\hline $\mathbf{H 2}_{\mathbf{1}}$ & $\begin{array}{l}\text { Perceived ease of use has relationship with the adoption of social media in } \\
\text { Halal SMEs }\end{array}$ \\
\hline
\end{tabular}

\begin{tabular}{|l|l|}
\hline $\mathbf{H 3}_{\mathbf{0}}$ & $\begin{array}{l}\text { Perceived trust has no relations hip with the adoption of social media in Halal } \\
\text { SMEs }\end{array}$ \\
\hline $\mathbf{H 3}_{\mathbf{1}}$ & $\begin{array}{l}\text { Perceived trust has relationship with the adoption of social media in Halal } \\
\text { SMEs }\end{array}$ \\
\hline
\end{tabular}

\section{RESEARCH METHODOLOGY}

The quantitative research based on the survey, which is questionnaire was applied in this study. Questionnaire was distributed to the top management, experts, entrepreneurs, experience employees and related employees who are contributing to the adoption of social media in Halal SMEs. The researcher used questionnaire to answer all the research question and research objectives and the target respondents are top management, experts, entrepreneurs, experienced employees and related employees in Halal SMEs industry.

The focus of this study is based on the food and beverages industry in Halal SMEs. The locations chosen for 
distributed the research questionnaires were at MIHAS exhibition, Kuala Lumpur Convention Centre, KLCC, Malaysia. MIHAS 2014 was held from 9 - 12 April 2014.

\section{FINDINGS AND DISCUSSION}

This chapter presents the analysis and findings of this study. The analysis and findings will be focusing based on the objectives of this study were to determine the relationship between the factors influence and the adoption of social media and to investigate the factor that influences more to the adoption of social media. This chapter analyzes the quantitative of 150 questionnaires that have been distributed at MIHAS exhibition at Kuala Lumpur Convention Centre. A Pearson correlation analysis was conducted to examine whether there is a relationship between the three variables in this research with the adoption of social media in food and beverage industry at Halal SMEs. Correlation analysis also had been used to test the hypothesis of this research.

Objective 1 : To determine the relationship between the factors influence and the adoption of social media.

The overview results are as follows:

Table 1: Pearson Correlation Coefficient

\begin{tabular}{|c|c|c|c|c|}
\hline & & $\begin{array}{l}\text { Perceived } \\
\text { Usefulness }\end{array}$ & $\begin{array}{c}\text { Perceived } \\
\text { Ease of Use }\end{array}$ & $\begin{array}{c}\text { Perceived } \\
\text { Trust }\end{array}$ \\
\hline Perceived Usefulness & $\begin{array}{l}\text { Pearson Correlation } \\
\text { Sig. (2-tailed) } \\
\mathrm{N}\end{array}$ & 150 & $\begin{array}{r}.816^{* *} \\
.000 \\
150\end{array}$ & $\begin{array}{r}.671^{* *} \\
.000 \\
150\end{array}$ \\
\hline Perceived Ease of Use & $\begin{array}{l}\text { Pearson Correlation } \\
\text { Sig. (2-tailed) } \\
\mathrm{N}\end{array}$ & $\begin{array}{r}.816^{* *} \\
.000 \\
150\end{array}$ & 150 & $\begin{array}{r}.667^{* *} \\
.000 \\
150\end{array}$ \\
\hline Perceived Trust & $\begin{array}{l}\text { Pearson Correlation } \\
\text { Sig. (2-tailed) } \\
\mathrm{N}\end{array}$ & $\begin{array}{c}.671^{* *} \\
.000 \\
150\end{array}$ & $\begin{array}{r}.667^{* *} \\
.000 \\
150\end{array}$ & 150 \\
\hline Adoption of Social Media & $\begin{array}{l}\text { Pearson Correlation } \\
\text { Sig. (2-tailed) } \\
\mathrm{N}\end{array}$ & $\begin{array}{r}.917^{* *} \\
.000 \\
150\end{array}$ & $\begin{array}{r}.864^{* * 4} \\
.000 \\
150\end{array}$ & $\begin{array}{r}.689^{* *} \\
.000 \\
150\end{array}$ \\
\hline
\end{tabular}

**. Correlation is significant at the 0.01 level (2-tailed).

Based on Table 1 above, it shows the significant value for all the variables. The value of significant in perceived usefulness, perceived ease of use and perceived trust variables entire are 0.000 , which have a significant value of $p<0.05$. There are significant values in their relationship between the independent variables and dependent variable. It is mean that all the variables of perceived usefulness, perceived ease of use and perceived trust have a significant relationship with the adoption of social media.

Table 2: The Relationship between Perceived Usefulness (PU) and the Adoption of Social Media Hypothesis 1 
H10 Perceived usefulness has no relationship with the adoption of social media in Halal SMEs

H1 1 Perceived usefulness has relationship with the adoption of social media in Halal SMEs

\begin{tabular}{|ll|r|r|}
\hline & \multicolumn{1}{|c|}{$\begin{array}{c}\text { Perceived } \\
\text { Usefulness }\end{array}$} & $\begin{array}{r}\text { Adoption of } \\
\text { Social Media }\end{array}$ \\
\hline Perceived Usefulness & Pearson Correlation & 1 & $.917^{* *}$ \\
& Sig. (2-tailed) & .000 \\
& $\mathrm{~N}$ & 150 & 150 \\
\hline Adoption of Social Media & Pearson Correlation & $.917^{* * *}$ & 1 \\
& Sig. (2-tailed) & .000 & 150 \\
& $\mathrm{~N}$ & 150 & \\
\hline
\end{tabular}

The result shows the Pearson's r-value is 0.917 . This number is very close to 1 . While, the Sig. (2-Tailed) value is 0.000 . This value is less than 0.05 . Correlation is significant at the 0.01 level. This result of the correlation indicates that higher level of perceived usefulness scores are associated with higher level of the adoption social media. This means that changes in perceived usefulness is very strongly correlated with changes in the adoption of social media. The results revealed a significant and positive relationship ( $r=0.917$, $\mathrm{p}<0.05, \mathrm{~N}=150$ ). The researcher rejects the null hypothesis and accepts the alternative hypothesis.

\section{H1 Aerceived usef ulness has relationship with the adoption of social media in Halal SMEs}

Table 3: The Relationship between Perceived Ease of Use (PEoU) and the Adoption of Social Media

H20 Perceived ease of use has no relationship with the adoption of social media in Halal SMEs

$\mathbf{H 2}_{1}$ Perceived ease of use has relationship with the adoption of social media in Halal SMEs

\begin{tabular}{|ll|r|r|}
\hline & $\begin{array}{c}\text { Perceived Ease } \\
\text { of Use }\end{array}$ & $\begin{array}{c}\text { Adoption of } \\
\text { Social Media }\end{array}$ \\
\hline Perceived Ease of Use & $\begin{array}{l}\text { Pearson Correlation } \\
\text { Sig. (2-tailed) }\end{array}$ & 1 & $.864^{* * *}$ \\
& $\mathrm{~N}$ & 150 & .000 \\
& Pearson Correlation & $.864^{* *}$ & 150 \\
& Sig. (2-tailed) & .000 & 1 \\
& $\mathrm{~N}$ & 150 & 150 \\
\hline
\end{tabular}

\section{Hypothesis 2}

\footnotetext{
**. Correlation is si gnificant at the 0.01 level (2-tailed).
}

The result shows the Pearson's $r$-value is 0.864 . This number is very close to 1 . While, the Sig. (2-Tailed) value is 0.000 . This value is less than 0.05 . Correlation is significant at the 0.01 level. This result of the correlation indicates that higher level of perceived ease of use scores are associated with higher level of the adoption social media. This means that changes in perceived ease of use are very strongly correlated with changes in the adoption of social media. The results revealed a significant and positive relationship $(r=0.864$, $\mathrm{p}<0.05, \mathrm{~N}=150$ ). The researcher rejects the null hypothesis and accepts the alternative hypothesis. 


\section{H2A Perceived ease of use has relationship with the adoption of social media in Halal SMEs}

Table 4: The Relationship between Perceived Trust (PT) and the Adoption of Social Media

\section{Hypothesis 3}

$\mathbf{H 3}_{\mathbf{0}}$ Perceived trust has no relationship with the adoption of social media in Halal

SMEs

$\mathbf{H 3}_{1}$ Perceived trust has relationship with the adoption of social media in Halal

SMEs

\begin{tabular}{|ll|r|r|}
\hline & & $\begin{array}{r}\text { Adoption of } \\
\text { Social Media }\end{array}$ \\
\hline Perceived Trust & Perceived Trust & $.689^{* *}$ \\
& Sig. (2-tailed) & 1 & .000 \\
& $\mathrm{~N}$ & 150 & 150 \\
\hline Adoption of Social Media & Pearson Correlation & $.689^{* *}$ & 1 \\
& Sig. (2-tailed) & .000 & \\
& $\mathrm{~N}$ & 150 & 150 \\
\hline
\end{tabular}

The result shows the Pearson's r-value is 0.689 . This number is very close to 1 . While, the Sig. (2-Tailed) value is 0.000 . This value is less than 0.05 . Correlation is significant at the 0.01 level. This result of the correlation indicates that higher level perceived trust scores are associated with high level of the adoption social media. This means that changes in perceive trust are strongly correlated with changes in the adoption of social media.

The results revealed a significant and positive relationship $(r=0.689, p<0.05, N=150)$. The researcher rejects the null hypothesis and accepts the alternative hypothesis.

\section{$\mathrm{H}_{\mathrm{A}}$ Perceived trust has relationship with the adoption of social media in Halal SMEs}

According to the data analysis result, it shows that all the three variables (perceived usefulness, perceived ease of use, perceived trust) in this study have their relationship with dependent variables (adoption of social media). The entire result for the variables also has a significant value. There is a significant very strong positive relationship exists between both perceived usefulness $(r=0.917, p<0.05)$ and perceived ease of use $(r=0.864, p<0.05)$ with the adoption of social media. While there is a significant strong positive relationship exist between perceived trust with the adoption of social media $(r=0.689, p<0.05)$. The researcher also rejects the entire null hypothesis and accepts the alternative hypothesis.

Objective 2: To investigate the factor that influences more to the adoption of social media.

Table 5: Regression Analysis for Perceived Usefulness (PU) and the Adoption of Social Media 


\section{Model Summary}

\begin{tabular}{|l|r|r|r|r|}
\hline Model & \multicolumn{1}{|c|}{$\mathrm{R}$} & R Square & \multicolumn{1}{c|}{$\begin{array}{c}\text { Adjusted R } \\
\text { Square }\end{array}$} & $\begin{array}{c}\text { Std. Error of the } \\
\text { Estimate }\end{array}$ \\
\hline 1 & $.917^{\mathrm{a}}$ & .841 & .840 & .1446 \\
\hline
\end{tabular}

a. Predictors: (Constant), Perceived Usefulness

\section{ANOVA $^{\mathrm{a}}$}

\begin{tabular}{|ll|r|r|r|r|r|}
\hline Model & & Sum of Squares & df & Mean Square & F & Sig. \\
\hline 1 & Regression & 16.370 & 1 & 16.370 & 783.355 & $.000^{\mathrm{b}}$ \\
& Residual & 3.093 & 148 & .021 & & \\
& Total & 19.463 & 149 & & & \\
\hline
\end{tabular}

a. Dependent V ariable: Adoption of Social Media

b. Predictors: (Constant), Perceived Usefulness

\section{Coefficients $^{\mathrm{a}}$}

\begin{tabular}{|c|c|c|c|c|c|c|}
\hline \multirow{2}{*}{\multicolumn{2}{|c|}{ Model }} & \multicolumn{2}{|c|}{$\begin{array}{l}\text { Unstandardized } \\
\text { Coefficients }\end{array}$} & \multirow{2}{*}{$\begin{array}{c}\begin{array}{c}\text { Standardized } \\
\text { Coefficients }\end{array} \\
\text { Beta }\end{array}$} & \multirow[b]{2}{*}{$\mathrm{t}$} & \multirow[b]{2}{*}{ Sig. } \\
\hline & & B & Std. Error & & & \\
\hline & (Constant) & .305 & .124 & & 2.456 & .015 \\
\hline & Perceived Usefulness & .922 & .033 & .917 & 27.988 & .000 \\
\hline
\end{tabular}

a. Dependent V ariable: Adoption of Social Media

Based on the table, the result shows that the $r$ value is 0.917 and the $r 2$ value is 0.841 . It shows that this factor has the very strong influence towards the adoption of social media $(\beta=0.917)$ because it approaching the value of one. It means that, $84 \%$ of the perceived usefulness factor is influencing the adoption of social media. Based on regression analysis, the perceived usefulness is significant predictors of the adoption of social media. The standard Beta indicates the strength and direction of the relationship $(B=0.917, t=27.988$, $\mathrm{p}<0.05)$. High levels of perceived usefulness factors correspond to a higher overall of the adoption of social media.

Table 6: Regression analysis for Perceived Ease of Use (PEoU) and the Adoption of Social Media

\section{Model Summary}

\begin{tabular}{|l|r|r|r|r|}
\hline Model & $\mathrm{R}$ & R Square & \multicolumn{1}{c|}{$\begin{array}{c}\text { Adjusted R } \\
\text { Square }\end{array}$} & $\begin{array}{c}\text { Std. Error of the } \\
\text { Estimate }\end{array}$ \\
\hline 1 & $.864^{\mathrm{a}}$ & .746 & .744 & .1827 \\
\hline
\end{tabular}

a. Predictors: (Constant), Perceived Ease of Use

\section{ANOVA $^{\mathrm{a}}$}

\begin{tabular}{|ll|r|r|r|r|r|}
\hline Model & & Sum of Squares & df & Mean Square & F & Sig. \\
\hline 1 & Regression & 14.522 & 1 & 14.522 & 434.965 & $.000^{\mathrm{b}}$ \\
& Residual & 4.941 & 148 & .033 & & \\
& 19.463 & 149 & & & \\
& Total & 14.463 & & & \\
\hline
\end{tabular}

a. Dependent Variable: Adoption of Social Media

b. Predictors: (Constant), Perceived Ease of Use 


\section{Coefficients $^{\mathrm{a}}$}

\begin{tabular}{|c|c|c|c|c|c|}
\hline \multirow[b]{2}{*}{ Model } & \multicolumn{2}{|c|}{$\begin{array}{c}\text { Unstandardized } \\
\text { Coefficients }\end{array}$} & \multirow{2}{*}{$\begin{array}{c}\text { Standardized } \\
\text { Coefficients }\end{array}$} & \multirow[b]{2}{*}{$\mathrm{t}$} & \multirow[b]{2}{*}{ Sig. } \\
\hline & B & Std. Error & & & \\
\hline$($ Constant $)$ & .807 & .318 & & 2.540 & .013 \\
\hline Perceived Ease of Use & .903 & .043 & .864 & 20.856 & .000 \\
\hline
\end{tabular}

a. Dependent Variable: Adoption of Social Media

Based on the above table, the researcher used the regression analysis to look at which factors are influencing more to the adoption of social media. The result shows that the $r$ value is 0.864 and the r2 value is 0.746 . It shows that this factor has the very strong influence towards the adoption of social media ( $~=0.864$ ) because it approaching the value of one. It means that, $75 \%$ of the perceived ease of use factor is influencing the adoption of social media. Based on regression analysis, the perceived ease of use is significant predictors of the adoption of social media. The standard Beta indicates the strength and direction of the relationship $(B=0.864, t=20.856, p<0.05)$. High levels of perceived ease of use factors correspond to higher overall the adoption of social media.

Table 7: Regression analysis for Perceived Trust (PT) and the Adoption of Social Media

\section{Model Summary}

\begin{tabular}{|l|c|r|r|r|}
\hline Model & $\mathrm{R}$ & R Square & $\begin{array}{c}\text { Adjusted R } \\
\text { Square }\end{array}$ & $\begin{array}{c}\text { Std. Error of the } \\
\text { Estimate }\end{array}$ \\
\hline 1 & $.689^{\mathrm{a}}$ & .474 & .471 & .2629 \\
\hline
\end{tabular}

\section{ANOVA $^{\mathrm{a}}$}

\begin{tabular}{|ll|r|r|r|r|r|}
\hline \multicolumn{1}{|l|}{ Model } & Sum of Squares & df & Mean Square & F & Sig. \\
\hline 1 & Regression & 9.233 & 1 & 9.233 & 133.578 & $.000^{\mathrm{b}}$ \\
& Residual & 10.230 & 148 & .069 & & \\
& Total & 19.463 & 149 & & & \\
\hline
\end{tabular}

a. Dependent Variable: Adoption of Social Media

b. Predictors: (Constant), Perceived Trust

\section{Coefficients $^{\mathrm{a}}$}

\begin{tabular}{|c|c|c|c|c|c|c|}
\hline \multirow{2}{*}{\multicolumn{2}{|c|}{ Model }} & \multicolumn{2}{|c|}{ Unstandardized Coefficients } & \multirow{2}{*}{$\begin{array}{c}\begin{array}{c}\text { Standardized } \\
\text { Coefficients }\end{array} \\
\text { Beta }\end{array}$} & \multirow[b]{2}{*}{$\mathrm{t}$} & \multirow[b]{2}{*}{ Sig. } \\
\hline & & B & Std. Error & & & \\
\hline \multirow[t]{2}{*}{1} & (Constant) & .872 & .252 & & 3.467 & .001 \\
\hline & Perceived Trust & .753 & .065 & .689 & 11.558 & .000 \\
\hline
\end{tabular}

a. Dependent V ariable: Adoption of Social Media

Based on the above table, the result shows that the $r$ value is 0.689 and the $r 2$ value is 0.474 . It shows that this factor has the strong influence towards the adoption of social media $(\beta=0.689)$ because it approaching the value of one. It means that, $47 \%$ of the perceived trust factor is influencing the adoption of social media. Based on regression analysis, the perceived trust is significant predictors of the adoption of social media. The standard Beta indicates the strength and direction of the relationship $(B=0.689, t=11.558, p<0.05)$. High levels of perceived trust factors correspond to higher overall the adoption of social media.

The result shows that among the three independent variables, perceived usefulness is the factor that influences more to the adoption of social media in food and beverage industry at Halal SMEs with the 
highest value of $\beta=0.917, t=27.988, p<0.05$ and $R 2=0.841$ which is it approaching the value of one. It is also shown that $84 \%$ of perceived usefulness factor is influencing the adoption of social media rather than perceive ease of use $74 \%$ and the less influence factor, perceived trust for $47 \%$. A higher level of perceived usefulness is associated with higher levels of the adoption of social media.

\section{CONCLUSION}

The study has verified that there are important determinants of social media adoption using TAM elements which are perceived usefulness and perceived ease of use with additional factors which is perceived trust as part of the factors influencing the adoption of social media in Halal SMEs organization. This study had successfully used TAM to investigate the factors that contribute to the adoption of social media. In addition, the behavioral intention from TAM also had been added as a predictor or measure to the adoption of social media.

Generally, interpretive inquiry aims to characterize how people experience the world, the ways they interact together, and the settings in which these interactions take place (Parker, 2008). This involves the interpretation of meaningful human expressions, written, verbal and/or physical, involving namely human and social actions (Ahamat, 2013). Smith (1992) argues that human actions are those assertions people make based on reasons, intentions and motivations, while the idea of social must be added because the meanings ascribed to human actions, both by the actors and the interpreters, are determined by, and can only be understood within, a social meaning. Hence, interpretive inquiry may accommodate well for the future study in this area.

\section{REFERENCE LIST}

Ahamat, A. (2013). Entrepreneurial opportunity creation in the biotechnology industry in Malaysia. Sheffield: University of Sheffield.

Ahamat, A., \& Chong, S. C. (2014). Assessment of The Factors Influencing Entrepreneurs on The Biotechnology Business Venture. Proceedings of the 24th International Business Information Management Association Conference - Crafting Global Competitive Economies: 2020 Vision Strategic Planning and Smart Implementation, pp. 2171-2177.

Ahamat, A., \& Chong, S. C. (2015). Multi-Methodological Approaches in Qualitative Entrepreneurship Research. International Business Management, 9(4), 601-612.

http://dx.doi.org/10.3923/ibm.2015.601.612

Ahlqvist, Toni; Bäck, A., Halonen, M., Heinonen, S (2008). December 2012 "Social media road maps exploring the futures triggered by social media".

Andreas M., Kaplan. (2012) If you love something, let it go mobile: Mobile marketing and mobile social media 4x4. In: Business Horizons. RePEc:eee:bushor:v:55:y:2012:i:2:p:129-139.

Davis, F. D. (1989). Perceived Usefulness, Perceived Ease of Use and User Acceptance of Information Technology. MIS Quarterly, 13(3 (September)), 319-340.

Davis, F. D. (1989). Perceived usefulness, perceived ease of use, and user acceptance of information technology. MIS Quarterly, 13(3), 319-339.

Davis, F. D., Bagozzi, R. P., \& Warshaw, P. R. (1989). User Acceptance Of Computer Technology: A Comparison Of Two Theorical Models. Management Science

Davis, F. D., Bagozzi, R. P., \& Warshaw, P. R. (1989). User acceptance of computer technology: A comparison of two theoreticalmodels. Management Science, 35(8), 982-1003.

Davis, F.D., (1989). Perceived usefulness, perceived ease of use and user acceptance of information technology. MIS quarterly, 13(3), 319-339.

Davis, F.D., Bagozzi, R.P., \& Warshaw, P.R. (1989).User acceptance of computer technology: A comparison of two theoretical models. Management science, 35(8), 982-1003.

Kaplan Andreas M., Haenlein Michael (2010). "Users of the world, unite! The challenges and opportunities of social media". Business Horizons 53 (1). p. 61. 
Parker, L.D (2008) Interpreting interpretive accounting research. Critical Perspectives on Accounting, 19(6): 909-914.

Smith, J.K. (1992). Interpretive inquiry: A practical and moral activity. Entrepreneurship Theory and Practice, $31(2)$.

Venkatesh, V. and J.Y.L. Thong and X. Xu, 2012. Consumer acceptance and use of information technology: Extending the unified theory of acceptance and use of technology. MIS Q., 36: 157-178.

Waleed Mugaheed Al-Rahimi, M. S. (2013). Using TAM Model To Measure The Use Of. International Journal of Engineering Trends and Technology (IJETT) - Volume 5 number 2 - Nov 2013. 